\section{A Family of Devon}

Their Homes, Travels and Occupations. By Dr. Vaughan Cornish. Pp. viii $+56+10$ plates. (St. Leonards-on-Sea : King Bros. and Potts, Ltd., 1942.) $10 s, 6 d$.

D . VAUGHAN CORNISH is a geographer who, in addition to his scientific studies of waves on sea and land and kindred geophysical phenomena, has devoted particular attention to the resthetic aspects of natural scenery. $\mathrm{He}$ has long taken an active part in preserving the amenities of rural Fngland and is the donor of South Combe Farm on Sidmouth Cliffs as an open space in perpetuity.

At the beginning of last century, George Cornish, who had been an officer in the Royal Marines and served in India as an A.D.C. to Sir John Shore, purchased an estate at Salcombe Regis, now included in the Sidmouth Urban District, and there founded the Sidmouth branch of the family. Dr. Vaughan Cornish is one of his descendants, and in this book he traces associations of members of the whole ancestral group with the part of South Devon in which they had their homesteads. The book is, however, more than a genealogical record and presents a picture of the life of lesser country gentry farming their own lands from Tudor times to the present day.

Throughout this period the intellectual interests of one or another of the family have been influences for good in the history of England. So long ago as 1775, some letters from Dr. James Cornish, "On the Torpidity of Swallows and Martins", were published in the Philosophical Transactions. He was the first of the family to branch out into authorship, and a number of other members have worthily followed him in literary, artistic and scientific fields. On the natural history and country-tife sides, C. J. Cornish, a master at St. Paul's School, was a brilliant writer on these subjects in the Spectator and other journals. $\mathrm{He}$ was a brother of Dr. Vaughan Cornish, whose wide outlook and acute vision have maintained the cultural tradition of the family which he represents so well.

\section{Practical Emulsions}

A Handbook of Emulsions, Emulsifiers and Methods of Formulating and Making Emulsions of Practical Value in Industry. By H. Bennett. Pp. $\mathrm{x}+462$. (Brooklyn, N.Y.: The Chemical Publishing Co., Inc., 1943.) 5 dollars.

$7 \mathrm{HE}$ principal object of this book is to deal, in reasonably small compass, with emulsions for the practical worker. Concentrating upon the art of making and applying emulsions, it touches only lightly upon the theoretical aspects, and illustrates these main themes by reference to practical usage.

Rather more than half the book is devoted to emulsion formulæ and directions for formulation. The remainder, under the term "General", outlines such topics as emulsifying agents, types of emulsions and assessment of stability, general methods of preparation and types of equipment employed, together with the related topics of foams, dispersing and wetting agents, and demulsifying and defoaming agents. While much useful practical information is to be found in this part, it does give the very definite impression that emulsion practice is still carried on as an empirical art with very little guidance from an understanding of the basic factors involved.
Since the theoretical aspects are touched upon, albeit only lightly, a brief but lucid exposition of modern advances would have been beneficial in enabling the practical worker to appreciate some of these more fundamental factors. In this connexion one is surprised to see the orientated wedge theory of emulsification given so much prominence. It is felt that this part could with advantage have been considerably reduced, leaving all theory to specialized treatises on the subject.

The second part, under the heading of "Formulas", gives an excellent idea of the multitudinous applica. tions for emulsions : agricultural sprays, cutting oils, cosmetics, foods, lacquers, lubricants, paints, paper, waterproofing and so on. No less varied are the ingredients used. The emulsion technologist should find these recipes very useful.

The book is well printed and typographical mistakes are few.

A. E. Alexander.

\section{War-Time Food for Mother and Child}

By Dr. Geoffrey Bourne. Pp. 78. (London, New York and Toronto: Oxford University Press, 1942.) $2 s$. $6 d$. net.

7 HE Minister of Food has shown his appreciation of the special needs of pregnant and nursing women and of growing children by the special allowances that he has made for these groups. However, these requirements are not so well realized by the general public. Anything that hammers in the fact that pregnant and nursing women and young children are the most vulnerable of our citizens is welcome. Dr. Bourne's book gives a clear explanation of the requirements of pregnancy; this is enlivened by information about the development of the fœtus not commonly found in books on nutrition. He might, perhaps, have brought out more clearly the fact, obvious but often overlooked, that the nursing woman has to supply all the constituents of her milk either from her food or from her own body. The extra needs during lactation are therefore more unquestionable than during pregnancy.

Dr. Bourne gives detailed advice about diets, suited to present conditions, from early pregnancy to school years. In some respects this is less satisfactory than the account of requirements and may be unrealistic. For example, as breakfast for a pregnant woman : "In place of orange or lemon juice eat black and red currants or drink infusions of hip and haws when they are available... The water left, when boiling vegetables... can be flavoured with Marmite or meat extract and then make a pleasant drink. ... After the vitamin $\mathrm{C}$ supplement a herring or kipper, if obtainable, may be eaten instead of an egg. . . ." How many people could get currants, during their short season, in the past two years? Why not tomatoes, which have a longer season and have been distributed widely if erratically? What proportion of breakfasts can supply egg or fish ? The vegetable water would be kept from the previous day; how much ascorbic acid would it contain unless kept in a refrigerator? Such advice tends to undo the good done by the valuable exposition of special requirements. In the more general discussion of diet, Dr. Bourne does not bring out the special importance of green vegetables - the food of which we can get more than we could in peace-time.

With these criticisms the book can be recommended for the material that is not found in other books on nutrition. 